\title{
Poly-crystalline low-loss aluminium oxide waveguides
}

Hendriks, W. A. P. M., Dijkstra, M., Hegeman, I., Segerink, F., Keim, E., et al.

W. A. P. M. Hendriks, M. Dijkstra, I. Hegeman, F. B. Segerink, E. G. Keim, M. J. Dikkers, S. M. García-Blanco, "Poly-crystalline low-loss aluminium oxide waveguides," Proc. SPIE 11689, Integrated Optics: Devices, Materials, and Technologies XXV, $116890 Z$ (5 March 2021); doi: 10.1117/12.2578141

SPIE. Event: SPIE OPTO, 2021, Online Only 


\title{
Poly-crystalline low-loss aluminium oxide waveguides
}

\author{
W.A.P.M. Hendriks ${ }^{\mathrm{a}}$, M. Dijkstra ${ }^{\mathrm{a}}$, I. Hegeman ${ }^{\mathrm{a}}$, F.B. Segerink ${ }^{\mathrm{a}}$, E.G. Keimª ${ }^{\mathrm{a}}$ M.J. Dikkers ${ }^{\mathrm{a}}$, \\ S.M. García-Blanco ${ }^{\mathrm{a}}$ \\ ${ }^{a}$ MESA+ Institute, University of Twente, P.O. Box 217, 7550 AE, Enschede, The Netherlands
}

\begin{abstract}
Luminescence quenching due to ion cluster formation in erbium ion doped amorphous aluminium oxide, limits the maximum doping concentration that can be incorporated into the material and, consequently, the maximum achievable optical gain. By controlling the reactive sputtering deposition parameters, layers with different morphologies can be deposited. In this work, we investigate low propagation loss poly-crystalline aluminium oxide thin films and the effect of erbium doping on the crystallinity. We have developed a reactive sputter process to reproducibly obtain high refractive index $(\mathrm{n} \sim 1.72$ at $633 \mathrm{~nm})$ poly-crystalline thin films with very low slab waveguide losses from the near-UV to the midinfrared wavelength range. Slab waveguide losses as low as $1.8 \mathrm{~dB} / \mathrm{cm}$ at $407 \mathrm{~nm}$ and less than $0.1 \mathrm{~dB} / \mathrm{cm}$ at $1550 \mathrm{~nm}$ of wavelength have been experimentally characterized. Both the undoped and erbium doped layers were deposited by reactive sputter coating with, a set substrate temperature of $700^{\circ} \mathrm{C}$. Preliminary TEM analyses show no discernible change in the crystallinity of the doped layers with respect to their undoped counterparts. The high optical quality of this material, in combination with a potentially increased rare-earth ion doping concentration, could pave the way towards high-gain on-chip amplifiers in different wavelength ranges and efficient on-chip lasers.
\end{abstract}

Keywords: Aluminium oxide, refractive index, low loss, sputtering, erbium.

\section{INTRODUCTION}

Erbium-doped fibre amplifiers (EDFAs) are a key component in today's telecommunications network ${ }^{1}$. For long distance high-speed communications optical fibre networks are well established and without competitor ${ }^{2}$. They are however not suitable to meet the demand and requirements imposed by the trend for high speed data transmission at ever shorter length scales. To fulfil the promise of higher data transmission densities and rates at lower energy expenditure by the inclusion of optical links at ever shorter distances such as in board and chip to chip, miniaturized versions of optical fibre components are needed. For erbium doped applications, aluminium oxide $\left(\mathrm{Al}_{2} \mathrm{O}_{3}\right)$ has been shown great promise for the realization of on chip amplifiers ${ }^{3}$ and lasers ${ }^{4}$. Integration with both the silicon-on- insulator ${ }^{5}$ and silicon sitride ${ }^{6}$ platforms has been shown, this last one in a double photonic layer configuration. Active and passive integration in a single $\mathrm{Al}_{2} \mathrm{O}_{3}$ layer has been demonstrated, removing the need for multiple lithography steps ${ }^{7}$. Unfortunately, the achievable gain of amorphous erbium doped $\mathrm{Al}_{2} \mathrm{O}_{3}$ is limited by luminescence quenching as a result of, amongst others, ion clustering ${ }^{8}$. A possible solution to reduce the ion clustering is embedding the ions in a crystal matrix. High gain per unit length has been recently shown in crystalline materials ${ }^{9}$ and in materials in which the separation of the erbium ions can be controlled at the atomic level ${ }^{10}$. This paper, describes the fabrication of low loss polycrystalline erbium doped $\mathrm{Al}_{2} \mathrm{O}_{3}$ slab waveguides. First, the sputter coating process is described, including the applied solution to compensate for the inherent drift of the system. Then, the effect induced in the layer properties by co-sputtering erbium will be discussed together with results on the guiding behaviour and optical characteristics of the doped layer.

\section{2. $\mathrm{AL}_{2} \mathrm{O}_{3}$ SPUTTER DEPOSITION}

Layers of $\mathrm{Al}_{2} \mathrm{O}_{3}$ were deposited using an AJA ATC $1500 \mathrm{RF}$ reactive co-sputtering system ${ }^{11}$ on silicon wafers with $8 \mu \mathrm{m}$ thick thermal oxide and $10 \mathrm{~cm}$ diameter. The system can host three 2 inch RF guns, one of which was equipped with an aluminium target ( $\mathrm{Al}, 99.9995 \%$ purity) and a second target equipped with an erbium target ( $\mathrm{Er}^{3+}, 99 \%$ purity), the third target was not used. The main deposition chamber is evacuated to a base pressure of $0.1 \mu$ Torr (i.e., $13 \mu \mathrm{Pa}$ ) to prevent incorporation of hydroxide ions in the layer, which induce absorption losses around $750 \mathrm{~nm}, 970 \mathrm{~nm}$, and $1400 \mathrm{~nm}^{12}$, and for rare-earth ion doped layers, induce luminescence quenching ${ }^{8}$. Depositions are performed with a constant RF power of $200 \mathrm{~W}$ applied to the aluminium target. For layers with erbium doping, an RF power of $16 \mathrm{~W}$ is applied to the second target. We estimate that erbium concentrations of $\sim 10^{20} \mathrm{~cm}^{-3}$ are introduced in the doped layer for an RF power of $16 \mathrm{~W}$ on the erbium target. This has been evaluated by comparing to the concentrations as a function of power determined by 
Wörhoff et al. in the same system ${ }^{11}$. The exact conditions of deposition and mainly the deposition rates were however different between both cases, thus we infer an order of magnitude agreement only.

The reactive sputter processes deposits the $\mathrm{Al}_{2} \mathrm{O}_{3}$ layer by accelerating argon ions towards the surface of the target, which in turn sputter aluminium atoms towards the substrate as schematically presented in Figure 1. The sustaining process of the magnetron discharge is the balance between the emission of secondary electrons from the ion bombardment on the target and the rate of electrons escaping the plasma. An magnetic field is used to prevent the electrons from escaping the target region before several argon ions are produced. This steady state discharge current, when operating the power supply at a constant power results in a discharge voltage that is thus a function of the secondary electron emission and the magnetic field strength ${ }^{13}$. While the magnetic field greatly increases the efficiency by the increase of ionization and therefore bombardment rate, it also confines this bombardment to an subregion of the target. Consequently, a trench is created in the target by erosion from consecutive depositions, causing the magnetic field to increase as the target gets thinner and the plasma therefore closer to the magnets. As a result, the discharge current and the deposition flux increase while the discharge voltage decreases ${ }^{14,15}$. Adding a reactive gas to this process further complicates finding a stable process as the reactive gas will create a compound by reacting with the metal on the surface of the target. The fraction of compound present on the target is determined by an equilibrium process between the compound forming rate at a given reactive gas partial pressure and the compound sputter rate removing compound from the target ${ }^{16,17}$. This equilibrium process also gives rise to hysteresis. A self-enforcing feedback loops can exist: starting from the low reactive gas partial pressure, an increased reactive gas partial pressure causes an increased compound fraction on the target which causes reduced sputter yield, causing less reactive gas gettering and thus an increased reactive gas pressure in the end causing the target to switch from an metallic to an compound state. When starting at a high oxygen partial pressure and reducing the pressure, the selfenforcing feedback loop runs in the opposite direction ${ }^{18}$. In this work the hysteresis is removed by using a large pump speed relative to the sputter rate, resulting in an negligible contribution of the getter effect from the deposition and a smooth logistic curve for the measured discharge voltage as a function of oxygen flow ${ }^{19}$.

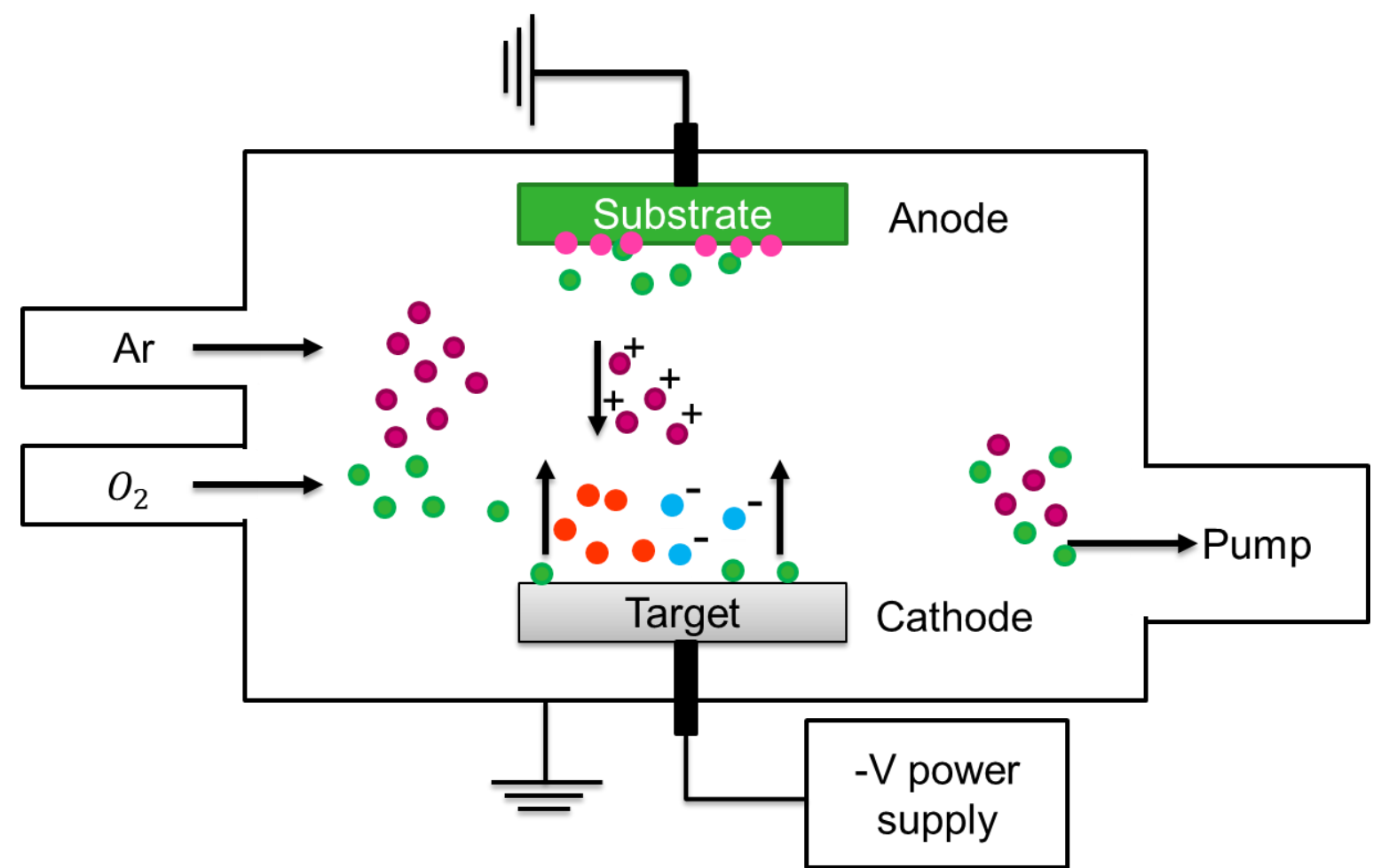

Figure 1 Schematic representation of the reactive sputter process for $\mathrm{Al}_{2} \mathrm{O}_{3}$ deposition. Where the Argon atoms (purple) are introduced along with the oxygen atoms (green). The argon atoms are ionized by the electrons (blue) emitted by secondary electron emission as a result of argon bombardment of the target. In addition to secondary electron emission, the argon bombardment also causes aluminium atoms (red) as well as oxygen atoms, from compound formed on the target, to accelerate towards the substrate. On the substrate surface the aluminium and oxide adatoms diffuse to form the compound $\mathrm{Al}_{2} \mathrm{O}_{3}$, (pink). In order for the process to occur under vacuum the added gasses are also pumped by a vacuum pump resulting in an constant process pressure. 


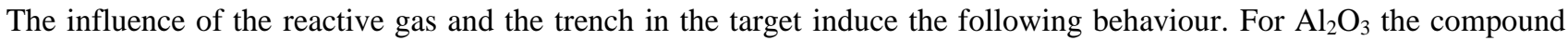
sputter yield is lower than that of metal, while the secondary electron emission is higher for compound. Therefore, the total sputter yield will decrease as the compound fraction of the target increases. The increased secondary electron emission and thus increased discharge current on the other hand further increases the ion bombardment rate albeit with a lower ion energy due to the reduced discharge voltage for our constant power process ${ }^{15}$. The result of the trench forming in the target is an unstable process over time. Given that layer morphology is very sensitive to the deposition rate and adatom energy ${ }^{20}$ consecutive depositions of $\mathrm{Al}_{2} \mathrm{O}_{3}$ at identical set values with respect to gas partial pressures and flows and power supply power will result in different deposition properties, layer morphologies and thus properties of the layer if no correction or feedback is applied. To operate at a more stable deposition condition, we employ a method as described by Emmerik et al. ${ }^{19}$. Before the start of the deposition process, the discharge voltage of the aluminium target as a function of oxygen flow into the chamber is measured. For low oxygen flows, the target is still mostly metallic. As the oxygen flow increases, the target starts oxidizing. Given the higher secondary electron emission yield of $\mathrm{Al}_{2} \mathrm{O}_{3}$ over that of aluminium, the voltage drops as the current increases to maintain a constant power on the target. While the oxygen is increased further, the discharge voltage approaches a minimum as the target reaches a fully oxidized state ${ }^{18,21-23}$. We define the position the process is operated at as the relative discharge voltage of the target defined as

$$
\eta_{o x}=\frac{V_{m}-V_{O_{2}}}{V_{m}-V_{o x}}
$$

where $V_{m}$ and $V_{\mathrm{O}_{2}}$ are the discharge voltage for a fully metallic target and a fully oxidized target surface respectively and $V_{o x}$ is the discharge voltage corresponding to the oxygen flow giving a relative discharge voltage state, $\eta_{o x}$. This relative discharge voltage state is used to compensate for the target erosion, as it ensures we remain close to the same oxidation state of the target ${ }^{18}$. Using the relative discharge voltage method allows us to reproduce layers over most of the target lifetime. For undoped layers, an relative discharge voltage of $5 \%$ was selected, since this value resulted in low loss amorphous low refractive index $(n \sim 1.65) \mathrm{Al}_{2} \mathrm{O}_{3}$ when the depositions were carried out at a set substrate temperature of $580{ }^{\circ} \mathrm{C}^{19}$. Further investigation revealed that layers grown at a set substrate temperature of $700{ }^{\circ} \mathrm{C}$ with a relative discharge voltage of $5 \%$ exhibit low propagation losses and a high refractive index ${ }^{24}$, that can be reproduced for many (15) runs using the relative discharge voltage method. In addition, an undoped layer grown using this method has been measured to have very low propagation loss of $0.025 \mathrm{~dB} / \mathrm{cm}$ at $1550 \mathrm{~nm}$, and propagation losses of $1.8 \mathrm{~dB} / \mathrm{cm}$ at $407 \mathrm{~nm},{ }^{24}$ which follow a Rayleigh scattering relation indicating these losses are scattering dominated ${ }^{24}$. The losses are similar to the recently reported losses for low refractive index $\mathrm{Al}_{2} \mathrm{O}_{3}$ deposited by atomic layer deposition ${ }^{25}$. The parameters used for the deposition of the high index layers both doped and undoped as analysed in this work at $700{ }^{\circ} \mathrm{C}$ are given in Table 1 .

While the deposition of undoped layers is reproducible and low loss has been demonstrated, the addition of erbium doping at a power of $16 \mathrm{~W}$ clearly changes the layer characteristics causing it to increase the scattering losses as can be seen in Figure 2. We have formulated several hypothesis for this result starting from the premise that an undoped layer is polycrystalline, as found by transmission electron microscopy (Figure 3 Transmission electron microscopy image of and undoped $\mathrm{Al}_{2} \mathrm{O}_{3}$ layer (left) and an Erbium doped $\mathrm{Al}_{2} \mathrm{O}_{3}$ layer (right) both grown at $700{ }^{\circ} \mathrm{C}$, with identical growth conditions. The insets of increased magnification are taken from the middle area of the layer as indicated, the exact location is however not exactly known. The respective SAD images are shown below with d-spacings corresponding to polycrystalline $\gamma$-phase Figure 3). First, the increased adatom energy implanted in the layer by the erbium ions, can increase the crystallite size in the layer causing increased Rayleigh scattering. Secondly, the deposited erbium in the layer consumes oxygen on the substrate, reducing the crystallization rate due to an increased required diffusion length for crystallization. Finally, the implanted erbium in the layer acts as an contamination preventing ordered crystalline growth, which would result in reduced crystallites. In all cases where the crystallite sizes are reduced we would initially expect reduced scattering losses, however another possibility is a reduced rate of crystallite formation leading to larger crystallites in an amorphous matrix finally leading to increased scattering losses ${ }^{20,26-28}$. In principle tuning the temperature of the substrate should allow us to tune the layer morphology, the $700^{\circ} \mathrm{C}$ is however at the maximal set temperature allowing us to only tune in one direction. As the reason for the decreased losses are undetermined at the moment, we instead choose to tune the relative discharge voltage as it can be both increased and Decreasing the relative discharge voltage will increase the deposition rate, thereby reducing the crystallization, while increasing the relative discharge voltage has the opposite effect ${ }^{13}$. For this reason depositions at $3 \%$ and $7 \%$ relative discharge voltage are performed to ascertain an explanation for the decreased layer quality as it pertains to low loss optical guiding. 
Table 1. Optimized Rf reactive sputtering process parameters

\begin{tabular}{|c|c|c|}
\hline Parameter & Value & Unit \\
\hline Argon flow & 30 & $\mathrm{sccm}$ \\
\hline Oxygen flow & $\begin{array}{l}\text { Undoped } 3.1 \\
\text { doped } 0.7,1.1,1.4\end{array}$ & $\mathrm{sccm}$ \\
\hline Relative discharge voltage & $\begin{array}{l}\text { undoped: } 5 \\
\text { doped } 3,5,7\end{array}$ & $\%$ \\
\hline Pressure & $\begin{array}{l}\text { undoped: } 3.6 \\
\text { doped: } 3.3,3.5,3.5\end{array}$ & mTorr \\
\hline Substrate set temperature & 700 & ${ }^{\circ} \mathrm{C}$ \\
\hline Target-substrate distance & 15.2 & $\mathrm{~cm}$ \\
\hline Power & 200 & $\mathrm{~W}$ \\
\hline Power erbium target & undoped:0 doped:16 & $\mathrm{W}$ \\
\hline
\end{tabular}

\section{RESULTS}

Characterization of all deposited layers is performed by measuring the refractive index and thickness of the layer using a Woollam M-2000 spectroscopic ellipsometer. To the data, obtained for the wavelengths from $600 \mathrm{~nm}$ up to $1690 \mathrm{~nm}$ by the ellipsometer, a two parameter Cauchy model is fitted. From the fit an expected layer thickness at the centre of the wafer and an expected refractive index at $1030 \mathrm{~nm}$ are determined as given in

. Using the data for all 15 deposited undoped layers deposited at $700{ }^{\circ} \mathrm{C}$ and $5 \%$ relative discharge voltage, the mean and standard deviation of the refractive index at $1030 \mathrm{~nm}$ and deposition rate are calculated. This allows for the comparison of the doped layers with the undoped layers fairly as a significant difference can be ascertained. In the second column the specific parameters of the undoped layer used for comparison of the TEM images are given. Clearly the refractive index of the doped layers is increased with respect to the undoped layers, which can be explained by a combination of erbium being a larger atom and therefore, exhibiting higher polarizability and an increased layer density and likely more crystallinity in the layer. The deposition rate, follows the expected behaviour as an increased relative discharge voltage decreases the deposition rate and increases the refractive index.

Table 2. Characteristic parameters for grown layers extracted from the ellipsometry data. The deposition rate is derived by dividing the found layer thickness by the deposition time. The first column gives the mean result of all undoped layers and the standard deviation of the deviation from the mean.

\begin{tabular}{|l|l|l|l|l|l|}
\hline \multicolumn{1}{|c|}{ Parameters } & \multicolumn{1}{|c|}{ Mean } & Undoped & Doped 1 & Doped 2 & Doped 3 \\
\hline Relative Discharge (\%) & 5 & 5 & 3 & 5 & 7 \\
\hline Doping (W) & 0 & 0 & 16 & 16 & 16 \\
\hline Refractive index (1030 nm) & $1.722 \pm 0.008$ & 1.727 & 1.7352 & 1.7374 & 1.7375 \\
\hline Deposition rate (nm/min) & $3.6 \pm 0.4$ & 3.6 & 3.7 & 3.0 & 2.8 \\
\hline
\end{tabular}

In addition to the ellipsometry, the optical guiding quality of every wafer is qualitatively controlled by prism coupling a helium neon laser in the layer and looking at the light propagation using a Metricon 2010/M prism coupler instrument. A good layer is defined as light propagation to the end of the wafer without a noticeable change in intensity as shown in the left images displayed in Figure 2. From these images it is clear that the undoped layer and the doped layer at $3 \%$ relative 
discharge voltage exhibit a uniform intensity until the border of the wafer, where border effects are expected as a result of the wafer holder used during deposition. When the relative discharge voltage is increased, clearly the number of scattering points increases and the light intensity decreases as it propagates.
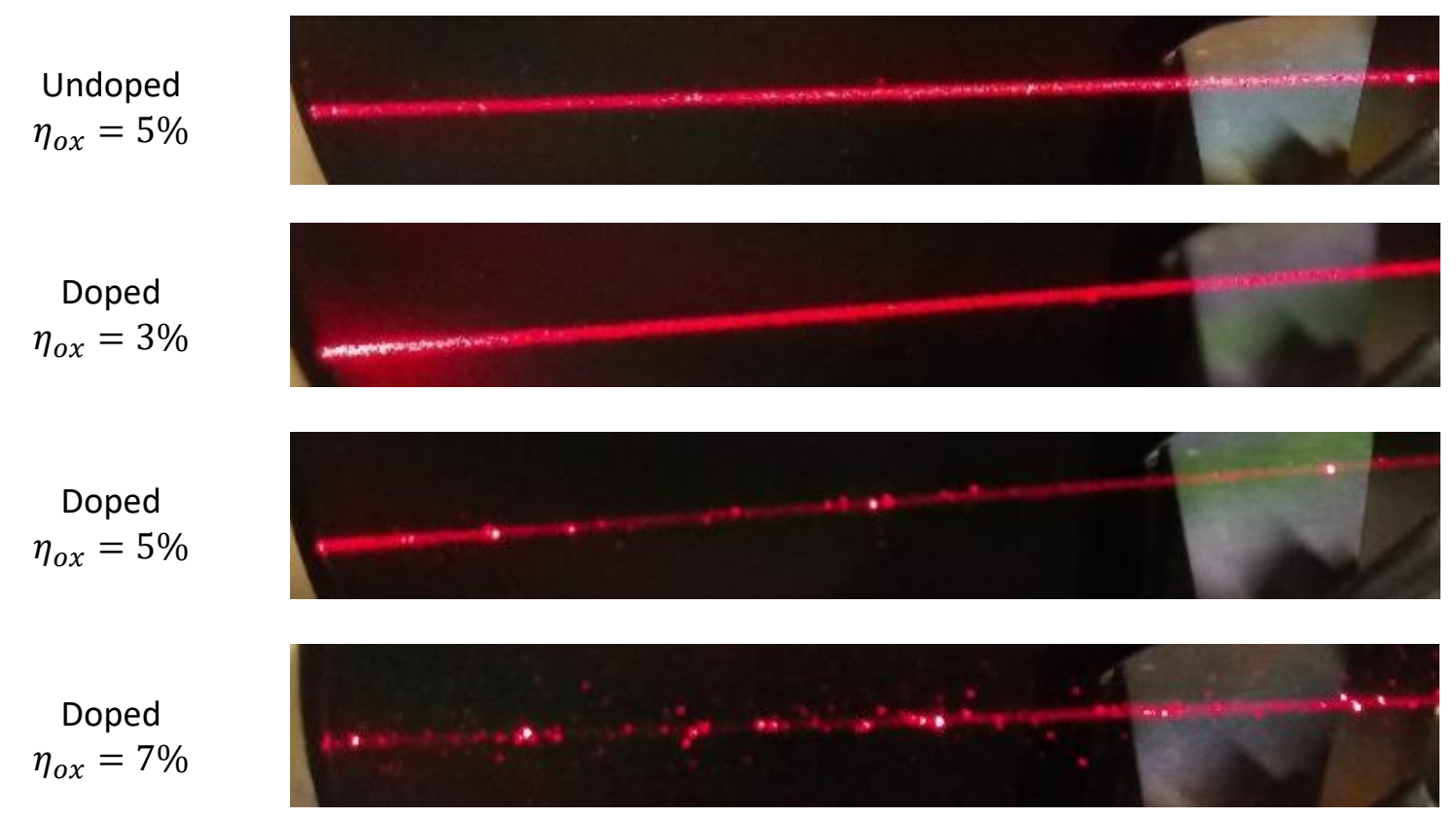

Figure 2 Prism coupled light propagation through a layer of $\mathrm{Al}_{2} \mathrm{O}_{3}$ at $633 \mathrm{~nm}$. The first image shows an undoped layer and shows a mostly continuous and uniform light distribution, followed by doped layers deposited with increased relative discharge voltage.

Combining the refractive index and optical guiding data, we seem to find support for the hypothesis that the rare earth ion co-sputtering causes the layer to increase the size of the formed crystallites in the layer. Both to verify this observation and investigate the degree of crystallinity an TEM sample of the undoped and doped layer grown at $5 \%$ relative discharge voltage are shown in Figure 3. Differences can be observed between the doped and undoped layers, indicating slightly increased crystallite sizes, especially on the zoomed insets. In addition the centre of the SAD image of the doped layer is less bright indicating an reduced contribution of amorphous material. These differences are however too small to conclude a significant difference between the layers is observed as the contrast and brightness of the images play a significant role in the interpretation. The brightness and contrast are influenced by the layer thickness of the analysed sample as well as the exact alignment of the electron bundle. We therefore conclude that no significant difference between the layers can be observed. The significant difference in the optical properties of the layer especially as it pertains to the scattering losses can still be explained, as Rayleigh scattering intensity scales with the $6^{\text {th }}$ power of the size of the scatter ${ }^{29}$. 

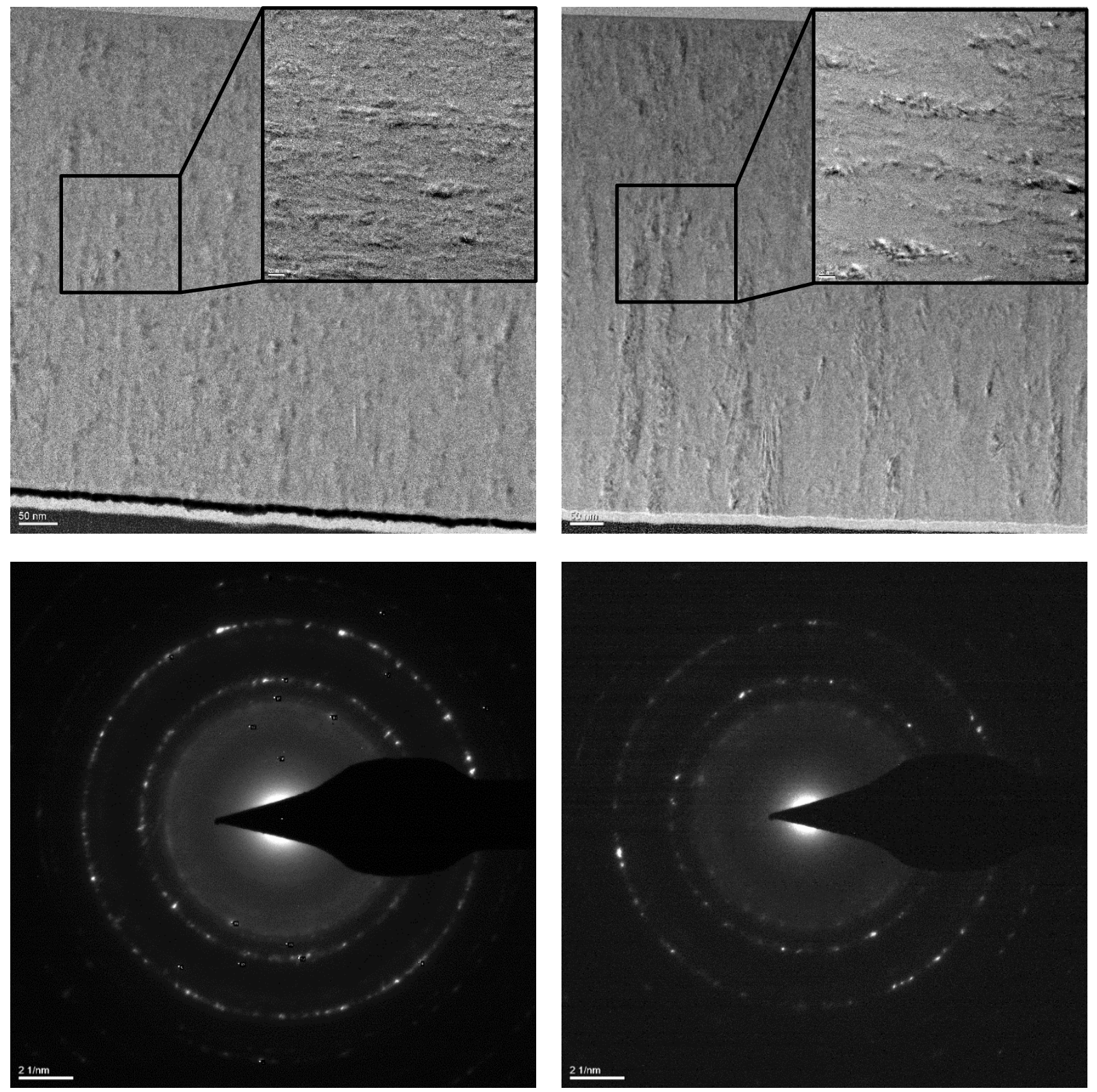

Figure 3 Transmission electron microscopy image of and undoped $\mathrm{Al}_{2} \mathrm{O}_{3}$ layer (left) and an Erbium doped $\mathrm{Al}_{2} \mathrm{O}_{3}$ layer (right) both grown at $700{ }^{\circ} \mathrm{C}$, with identical growth conditions. The insets of increased magnification are taken from the middle area of the layer as indicated, the exact location is however not exactly known. The respective SAD images are shown below with d-spacings corresponding to polycrystalline $\gamma$-phase $\mathrm{Al}_{2} \mathrm{O}_{3}$.

\section{CONCLUSIONS}

Low-loss erbium doped polycrystalline $\mathrm{Al}_{2} \mathrm{O}_{3}$ layers have been deposited using reactive co-sputtering. The polycrystalline character of the layer is promising for the possibility of reduced ion clustering and therefore limited luminescence quenching allowing for increased gain. Increased crystallinity as an consequence of co-sputtering erbium is likely but could not be definitively confirmed. The low-loss erbium doped $\mathrm{Al}_{2} \mathrm{O}_{3}$ achieved at an reduced relative discharge voltage relative to undoped layers, can be reproduced and further fine-tuned by a combination of substrate temperature and the relative discharge voltage. Increasing the doping concentration can therefore be performed while maintaining the low loss layer quality. Further research is needed to verify whether the polycrystalline character of the layer does indeed allow for increased doping concentrations reducing ion clustering induced luminescence quenching. 


\section{REFERENCES}

[1] Gnauck, A. H., Tkach, R. W., Chraplyvy, A. R. and Li, T., 'High-capacity optical transmission systems', J. Light. Technol. 26(9), 1032-1045 (2008).

[2] Essiambre, R. J. and Tkach, R. W., 'Capacity trends and limits of optical communication networks', Proc. IEEE 100(5), 1035-1055, Institute of Electrical and Electronics Engineers Inc. (2012).

[3] Mu, J., Dijkstra, M., Korterik, J., Offerhaus, H. and García-Blanco, S. M., 'High-gain waveguide amplifiers in Si 3 N 4 technology via double-layer monolithic integration’, Photonics Res. 8(10), 1634 (2020).

[4] Hendriks, W. A. P. M., Chang, L., van Emmerik, C. I., Mu, J., de Goede, M., Dijkstra, M. and Garcia-Blanco, S. M., 'Rare-earth ion doped $\mathrm{Al}_{2} \mathrm{O}_{3}$ for active integrated photonics', Adv. Phys. X 6(1), 1833753 (2021).

[5] Agazzi, L., Bradley, J. D. B., Dijkstra, M., Ay, F., Roelkens, G., Baets, R., Wörhoff, K. and Pollnau, M., 'Monolithic integration of erbium-doped amplifiers with silicon-on-insulator waveguides', Opt. Express 18(26), 27703 (2010).

[6] Mu, J., Dijkstra, M., Yong, Y. S., De Goede, M., Chang, L. and García-Blanco, S. M., 'Monolithic Integration of $\mathrm{Al}_{2} \mathrm{O}_{3}$ and $\mathrm{Si}_{3} \mathrm{~N}_{4}$ Toward Double-Layer Active-Passive Platform', IEEE J. Sel. Top. Quantum Electron. 25(5) (2019).

[7] van Emmerik, C. I., Dijkstra, M., de Goede, M., Chang, L., Mu, J. and Garcia-Blanco, S. M., 'Single-layer active-passive $\mathrm{Al}_{2} \mathrm{O}_{3}$ photonic integration platform', Opt. Mater. Express 8(10), 3049 (2018).

[8] Agazzi, L., Bernhardi, E. H., Wörhoff, K. and Pollnau, M., 'Impact of luminescence quenching on relaxationoscillation frequency in solid-state lasers', Appl. Phys. Lett. 100(1), 011109 (2012).

[9] Pan, A., Yin, L., Liu, Z., Sun, M., Liu, R., Nichols, P. L., Wang, Y. and Ning, C. Z., 'Single-crystal erbium chloride silicate nanowires as a Si-compatible light emission material in communication wavelength', Opt. Mater. Express 1(7), 1202 (2011).

[10] Rönn, J., Zhang, W., Autere, A., Leroux, X., Pakarinen, L., Alonso-Ramos, C., Säynätjoki, A., Lipsanen, H., Vivien, L., Cassan, E. and Sun, Z., 'Ultra-high on-chip optical gain in erbium-based hybrid slot waveguides', Nat. Commun. 10(1), 432 (2019).

[11] Wörhoff, K., Bradley, J. D. B., Ay, F., Geskus, D., Blauwendraat, T. P. and Pollnau, M., 'Reliable Low-Cost Fabrication of Low-Loss $\mathrm{Al}_{2} \mathrm{O}_{3}: \mathrm{Er}^{3+}$ Waveguides With 5.4-dB Optical Gain', IEEE J. Quantum Electron. 45(5), 454-461 (2009).

[12] Weik, M. H. and Weik, M. H., 'hydroxyl ion overtone absorption', [Computer Science and Communications Dictionary], Springer US, 742-742 (2000).

[13] Depla, D., [Magnetrons, reactive gases and sputtering], Diederik Depla (2013).

[14] Depla, D., Strijckmans, K. and De Gryse, R., 'The role of the erosion groove during reactive sputter deposition', Surf. Coatings Technol. 258, 1011-1015 (2014).

[15] Depla, D., Heirwegh, S., Mahieu, S., Haemers, J. and De Gryse, R., 'Understanding the discharge voltage behavior during reactive sputtering of oxides', J. Appl. Phys. 101(1), 013301 (2007).

[16] Berg, S. and Nyberg, T., 'Fundamental understanding and modeling of reactive sputtering processes', Thin Solid Films 476(2), 215-230 (2005).

[17] Depla, D., ['Magnetrons, reactive gases and sputtering'], Diederik Depla (2014).

[18] Strijckmans, K., Schelfhout, R. and Depla, D., 'Tutorial: Hysteresis during the reactive magnetron sputtering process', J. Appl. Phys. 124(24) (2018).

[19] van Emmerik, C. I., Hendriks, W. A. P. M., Stok, M. M., de Goede, M., Chang, L., Dijkstra, M., Segerink, F., Post, D., Keim, E. G., Dikkers, M. J. and García-Blanco, S. M., ' Relative oxidation state of the target as guideline for depositing optical quality RF reactive magnetron sputtered Al 2 O 3 layers ', Opt. Mater. Express 10(6), 1451 (2020). 
[20] Mahieu, S., Ghekiere, P., Depla, D. and De Gryse, R., 'Biaxial alignment in sputter deposited thin films', Thin Solid Films 515(4), 1229-1249 (2006).

[21] Depla, D., Tomaszewski, H., Buyle, G. and De Gryse, R., 'Influence of the target composition on the discharge voltage during magnetron sputtering', Surf. Coatings Technol. 201(3-4), 848-854 (2006).

[22] Strijckmans, K. and Depla, D., 'Modeling target erosion during reactive sputtering', Appl. Surf. Sci. 331, 185192 (2015).

[23] Madsen, N. D., Christensen, B. H., Louring, S., Berthelsen, A. N., Almtoft, K. P., Nielsen, L. P. and Bøttiger, J., 'Controlling the deposition rate during target erosion in reactive pulsed DC magnetron sputter deposition of alumina', Surf. Coatings Technol. 206(23), 4850-4854 (2012).

[24] Hendriks, W. A. P. M., Dijkstra, M., Emmerik, C. I. van, Hegeman, I. and García-Blanco, S. M., 'High refractive index low-loss aluminium oxide waveguides', Eur. Conf. Integr. Opt.(1), 2-4 (2020).

[25] West, G. N., Loh, W., Kharas, D., Sorace-Agaskar, C., Mehta, K. K., Sage, J., Chiaverini, J. and Ram, R. J., 'Low-loss integrated photonics for the blue and ultraviolet regime', APL Photonics 4(2), 026101 (2019).

[26] Petrov, I., Barna, P. B., Hultman, L. and Greene, J. E., 'Microstructural evolution during film growth', J. Vac. Sci. Technol. A Vacuum, Surfaces, Film. 21(5), S117-S128 (2003).

[27] Cougnon, F. G., Dulmaa, A., Dedoncker, R., Galbadrakh, R. and Depla, D., 'Impurity dominated thin film growth', Appl. Phys. Lett. 112(22), 221903 (2018).

[28] Miney, P. G., Colavita, P. E., Schiza, M. V., Priore, R. J., Haibach, F. G. and Myrick, M. L., 'Growth and Characterization of a Porous Aluminum Oxide Film Formed on an Electrically Insulating Support', Electrochem. Solid-State Lett. 6(10), B42 (2003).

[29] Cox, A. J., DeWeerd, A. J. and Linden, J., 'An experiment to measure Mie and Rayleigh total scattering cross sections’, Am. J. Phys. 70(6), 620-625 (2002). 